\title{
Analysis on the Characteristics of Speech in Chinese Network Forums
}

\author{
Ruihui $\operatorname{Han}^{1}$ \\ ${ }^{1}$ Humanities School, Jinan University, Zhuhai, Guangdong Province, China \\ Correspondence: Ruihui Han, Humanities School, Jinan University, Zhuhai, Guangdong Province, China. E-mail: \\ hanruihuihh@hotmail.com
}

Received: March 15, 2014 Accepted: April 24, 2014 Online Published: May 26, 2014

doi:10.5539/ass.v10n12p90

URL: http://dx.doi.org/10.5539/ass.v10n12p90

\begin{abstract}
Network forum has become a speech field of Chinese netizens to express their own ideas with the fast development of the network in China. This paper analyzes the characteristics of the speech in Chinese network forum by survey on the Netease BBS, one of the most important network forums in China. The characteristics of the forum speech conform to the features of the crowd described by the social psychologist Gustav Le Bon, which is innocent, impulsive and vulnerable to implication. In the forums, the individuals form the group and imitate each other automatically and unconsciously. With the effects of polarization, sleeper and stereotype, the extreme speech and rumors often come into being in that process, and have harmful influence to the social stability.
\end{abstract}

Keywords: network forum, speech, netizen, the crowd, effect of polarization, effect of sleeper, effect of stereotype

\section{Introduction}

With the increase of Chinese netizen, China has become the country with the largest number of netizens in the world. Network forums have become a place for netizens to express their opinions freely because the restrictions to the comments of netizens in network are reducing. In recent years, almost the entire explosive message in Chinese internet has come from network forums, whose influences on Chinese social opinion have become more overwhelming. The characteristics of netizen speech in Chinese network forums are the concern object of this paper.

Chinese network forum seems very confusing in the first glance. In a larger sense, network forum includes not only the BBS, but also QQ, MSN etc., because such chat tools have the function of group discussion. In the network forum, there are both much useful information and harmful information, so the network forum is a double-edged sword. With the group effect, the speech in the network forum would be out of control, and that is disadvantage to the stability of society.

\section{Background}

The population of Chinese netizen springs up fast and the uses of network become more diverse. The public still get the information from mainstream media today, but the network provides more and more information and influences the opinion of the public more significantly. The youth of China spend more time on network than that on television. As a source of information, the network plays an important role in the daily life of the public.

Although the public do not believe everything they get from the network, but the huge amount of information influences the attitude and emotion of the netizen. At least they would believe it later because of the sleeper effect, although they do not believe the information in the first glance. Some information comes from the mainstream media would be interpreted out of context, and be spread in the network, so the seriously false information comes into being.

The commercialization of the network forum is also a factor that gives birth to the false information. Making profit is the first goal of the commercialized forum. In order to catch the attention of the netizen, the forum would put up some fancy or even abnormal information. In fact, such information is not true, and most of the netizen do not believe that, but in the long run, it would have great influence and misleads the netizen.

In recent years, lots of the network events interrupt the normal living situation of the parties. The fact is distorted and magnified in the description and narrative of the network forum, and soon becomes the focus of the netizen. 
Some netizens do not believe such information but still spread and overstate the information. As a result, the defined impression of the parties is formed because of the group polarization. The parties would be the target of the language violence soon and the tragic ending is caused.

In current situation, some sensitive spheres such as medical treatment, housing etc. are the most important focus of Chinese netizens. The speech in such spheres would be very radical. Once the speech appears, the results of it would often be explosive.

The development of network facilitates the prosperity of economy and culture, but on the other side, it also brings about many disadvantages to the individual and society.

The network forum appeared in China about 15 years ago, and the growth of it is fast, with diverse variants of it, such as QQ group and Micro letter group etc., which can provide more instant and convenient connection for the users. The network forum is the ancestor of the following group connection tools, so the model of it is the fundamental form. Today, although the different tools of network connection spring up, the network forum is still active. The analysis of the network forum would show the fundamental characteristics of the network group connection.

\section{Literature Review}

One would finds 2053 results from 1985 to 2014 by searching the China National Knowledge Infrastructure with the subject keyword as "network forum". There were no more than 2 papers every year from 1985 to 1998 . From 1999 to 2008 , the number of the papers every year is $9,9,16,43,43,50,76,78,113,138$ respectively. The number reflects the increasing attention of the academic circle on network forum. In 2009, the number of the papers grew to 302 rapidly. After 2009 , the number of every year is more than 250 . The number of papers conforms to the development of the network forum.

Analysis of the network forum shows that from 1985 to 1998, the network forum was strange to ordinary Chinese. For example, the paper Good Place For talking everything under the Sun: Network Forum introduced the communication effect of the network forum. (Ma, B., \& Ma, Y., 1999), and the paper in the same year The Common Concepts of Internet explained the concept network forum. (Luo, 1999).

From 2000 to 2001, the relevant papers were Chinese Association of Journalist Propose to Establish Chinese Media Network Forum (Cheng, 2000) and The Development Trend of Chinese News Media Network Forum. China Publishing (Meng, 2001) etc., which discussed the establishment and the development trend of news media network forum. The papers indicate that in the two years, the network forum sprouted in China.

The paper The First Exploration on the Speech Style of Network Forum: Discussing the Typical Appearance of the Chat on Internet in the Perspective of Network Forum (Jiang, 2002) in 2002, The Complementation and Interaction between Network Forum and Newspaper (Chen \& He, 2003) in 2003, and On the Development and Utilization of Network Forum Information (Yang, 2004) in 2004 etc. show that the network forum developed in this period and the academic circle was interested in the features and the utilization of network forum.

From 2006 to 2007, some researchers noticed the defect and disharmony of the network forum. For example, The Effective Control on the Guidance of Public Opinion of Public Forum (Jiang, 2006) and The Standard of Order in Harmonious Network Forum (Wang, 2006) shew the instability of network forum speech and discussed the methods to control and guide it. It witnessed the fast development of network forum in China in this period, and more network events happened in 2007 than those in previous years.

From 2008 to 2009, the new research trend was to be more theoretical. The paper The Exploration on the Communication Model of Network Forum (Yang, 2008) discussed the communication model of network forum. Discussion on the Forming of Public Opinion in High School Network Forum (Ge, 2009) noticed the important function of high school network forum and studied the forming process of public opinion in high school network forum and the utilization of the process. The master thesis the quantitative analysis of BBS based on Social Network Analysis and Data Mining discussed the pattern of the communication of network social public opinion through quantitative analysis. (Zhuang, 2010).

From 2010 until now, the perspectives from which to study about the network forum became diverse; this was a new trend of network forum study. Among the perspectives the interdisciplinary study is the most used research pattern. Lots of researchers tried to study the network forum in the perspectives of education, advertisement, psychology, politics etc.

The disharmonious speech calls for more research. In the network forum, the model of speech is different from that in reality, but the network forum speech influences the reality greatly. The previous research has noticed the 
disharmony of the network forum speech, but the in-depth analysis of the phenomenon is still needed.

\section{Related Theories to Justify with the Research}

The paper will analyze the network forum speech in the perspective of group psychology. The network forum leads the individuals together to form the group, in which the individuals have the same goal, activity, and group norm and group consciousness. The theories of the group psychology are numerous, in which the famous is Gabriel Trade The Law of Imitation in 1890, which considers that human's social activities can only be explained by the thought of imitation; and Gustav Le Bon's The Crowd in 1895, which believes the group is innocent, stupid and impulsive; William McDougall's An Introduction to Social Psychology in 1920, which regards the forming the group as the instinct of human being. The psychologists' theories are related to the study of the network forum.

There are other theories related to the study. The first is the theory of group polarization put forward by James Stoner in 1961. The theory of group polarization considers the discussion could reinforce the opinion that held by the most of the group and make the ones who believe the opinion more steadfast, and then the tendency of the group is strengthened more, exceeding the average tendency of the previous group. In the network forum, one would find many examples of group polarization.

The theory of sleeper effect, which was put forward by H. C. Kelman and C. I. Hovlomd in 1953, is another theory related to the study. The theory believes that the information comes from the unreliable sources would influence the receiver more and more as time goes, and the influence of the information comes from the authoritative sources would decline. The information which comes from the network forum at first is not reliable, but it still influences the netizen. That can be explained by the theory of sleeper effect.

\section{Methodology}

\subsection{Sample Selection}

The analyzing object of this research is the Chinese Netease BBS. Other data of this research come from the research results of China Internet Network Information Center.

\subsection{Precision Analysis of the Sample}

Netease is one of the three largest Chinese web portals and has significant influence. The BBS of it is also one of the largest network forums in China. The Netease BBS has the typical characteristics of Chinese network forums. China Internet Network Information Center is an authorized network research agency, whose data is objective and impartial.

Netease BBS consists of columns such as news, entertainments, sports, military affairs and women, etc. Wherein, the mostly concerned pages are mainly social phenomena, news pictures, superstar forum, global pictures, housing story and decoration diary, etc.

The top three of the most active forums in Netease BBS are "social phenomena", "news pictures" and "superstar forum". Therefore, the netizen speech in these three forums is most representative. The paper will take the top three network forums as the objects of survey.

\subsection{Survey Design}

In the perspective of communication model, the sender, the content and the impact of the message are the most important factors. Those factors mentioned above are corresponding to the poster, content and the reply of the post respectively. So in the following, the paper will survey on the poster, content and the reply of the post in the network forum after introduction of the main content of the top three forums.

\subsection{Survey Results}

\subsubsection{Main Contents of the Top Three Forums in Netease BBS}

The survey on the main contents of the mostly concerned three forums as "social phenomena", "news pictures" and "superstar forum" are as follows:

The contents of the social phenomena forum is very rich, most of which are the posts related to society and people's livelihood. The posts in the news pictures forum, whose contents are mainly about news, are always updated according to the hot news topics. The main contents of the superstar forum are the entertainment information and the ridiculous things spread in streets and lanes, which focus mainly on superstars and entertainments.

However, the hottest posts, which are also the most in number, in the three forums are anti-corruption posts. The 
contents of those posts are relatively serious. Most of those posts contain the evidence and pictures related to the report. The posts revealing the unfairness of the society and corruptions reached about $80 \%$. Most of them are in the pages as "social phenomena" and "news pictures".

Apart from those three forums in Netease, the post titles of the column "Focus today" in the home page of the Netease are also very obvious. However, the contents of the "Focus today" are not cared by the common netizens. Generally, the poster of those contents is Netease, and the contents are similar with those of the mainstream official media.

\subsubsection{The Poster}

As for the poster, grass-roots in network are the most. Most of them are the disadvantaged groups in society, and the posts of the mainstream media and elite class are not the dominant ones in the network forums on the contrary.

According to the statistical results of China Internet Network Information Center, the main users of Chinese internet are teenagers. Wherein, the age group from 22 to 29 takes up the highest percentage. According to the statistical proportion in June 2013, it takes up 29.5\% of the total netizen number. The number of the users in junior and senior high schools, technical secondary schools and vocational schools takes up the highest percentage. According to the statistical proportion in June 2013, junior high school netizens take up $36.3 \%$ of the total netizen number; netizens from the senior high schools, technical secondary schools and vocational schools take up $32.3 \%$ of the total number of the netizen. From the aspect of occupational structure, the percentages of students and individual household/the self-employed are $26.8 \%$ and $17.8 \%$ respectively, who are the largest online group. From the aspect of income structure, the percentages of netizens with incomes as RMB 3001-5000 yuan, RMB 2001-3000 yuan and below RMB 500 yuan are the highest, $18.1 \%, 17.5 \%$ and $14.9 \%$ respectively. (CNNIC, 2013)

From the above data, we can see that the netizens in China are young and with low income and low education degree. In other words, the main part of Chinese netizen is the disadvantaged group.

\subsubsection{The Content of the Post}

As for the post contents, a large amount of them are meaningless. For instance, in the social phenomena forum, there are some posts named as "nfflulmyor", "edaqwvdzwb", "sasdfasdfasdf" and "uojarvegjt". Obviously, those headlines are created by knocking the keyboard randomly and such posts are not replied and with little click rate. Spoof posts are also very common in network forums. Generally, the headlines of those spoof posts are very attractive, while the contents of them are unexpected, which bring audience with a sense of being cheated. Some pictures in internets are also the results of spoof behaviors. Some pictures are completely different after being modified with PS software and added with new headlines and comments. Those pictures are spread frequently. Sometimes, they are treated as truths by some netizen. Numerous posts of such kind in the forums would cause a sense of confusion for the net suffers.

If those meaningless posts are excluded, the attractive posts in the forums are those expressing the dissatisfaction to the society, whose contents are always serious.

In such posts, some governmental officers become the attack object of the netizens in various forums, and that is very meaningful for anti-corruption. However, the contents of such posts are always created under the furious emotion of netizens, which cannot represent the truth. Though most of those posts reveal some social and official corruptions, they should be verified. The posts, such as "Disclosure: director of XXX bureau, XXX, sold a position at a price of tens of thousands" etc., would just be a kind of personal attack and do not represent the truth.

The unverified social rumors are also the important contents in network forums. For instance, the post headline, "A 5 year old boy died mysteriously in XXX province, insider says he was died of kidnapping", is similar with the headline of news, but the contents of the post is not a piece of news but a network hearsay. However, those hearsays exist as rumors.

\subsubsection{Replies}

The replies of posts in forums can be divided into three kinds as following:

1) Nonsense replies. Such kind of replies is often composed by "support", "passer-by" or several meaningless head portraits. The content of such replies are hollow, which can only represent that the followers have read the post.

2) Replies for drawing attention. The contents of such kind of replies are absolutely irrelevant to the post, with 
which the repliers want to draw concerns through the main post. For instance, in some posts with high click rate, some followers like to introduce the contents concerned by him. Those posts are often related to anti-corruption, and through the irrelevant replies the repliers want to draw much attention to their corruption related contents through the main post.

3) Replies for abreaction. The contents of such kind of replies are of the kind of abreaction. Such posts are featured of curse, language attack or irresponsible remark.

Those replies have such following characteristics:

1) Most of the replies in forums are composed by no more than 10 words, which reflects that the replier do not think thoroughly about the issues of the posts.

2) The contents of the replies are often having the same opinions, which are mainly the dissatisfied and angry speech.

3) The general click times of every post in the social phenomena forum in Netease is about 400 , and the general click times of one post in the news pictures is about 2000 and the general click times of one post in the superstar forum is about 300 . Form those data we can see that the ordinary netizens tend to find the news and the hearsays.

\section{Research Analysis}

Netease BBS has the characteristics of the group. The individuals form the group automatically in the BBS. Most of the individuals are the youth or have no good educational experience, that conforms to the characteristics that mentioned by Gustav Le Bon's The Crowd. The netizen in the BBS is impulsive, innocent and vulnerable to implication. In the speech of the BBS, the individuals imitate the others unconsciously.

From the survey results we can see the characteristics of the speech in Chinese network forums are as follows:

1) Most of the posts and replies in the network forum have the characteristic of abreaction. As the social pressure increases and the gap of wealth become wider and wider, the disadvantaged groups cannot find place in the actual discourse space. Therefore, they turned to the network to relieve their feelings. Network is anonymous and virtual, so their abreactions cannot be traced by ordinary people. Therefore, a large amount of speech is not restricted in network, so the network becomes a platform for abreaction.

Many posters are not clear about the fact, but they would overstate the events in the posts, or even spread rumors to create troubles. That shows the posts in the network forum have the characteristic of abreaction. In the forums, the posters diatribe without thinking thoroughly in the posts or replies. Freud believed the civilization is formed by the factors of institution, law and ethic etc., which are the results of suppression on the instinctive impulse. In the real world, one would be restricted by the civilization factors more, but in the virtual world, one would be freer because of less strict, but the freedom brings about not only the convenient communication but also the confusion of the network forum speech. The posters or the ones reply in the forums would speak anything they want to say or curse in order to abreact. In this sense, we can say that some of the network forums belong to the world which has less civilization. Or even to an extent, some forums can be said as the savage world.

2) In the forums, most comments exist in the form language violence. "Language violence is the application of insulting and discriminatory language as fling abuses, slander, scorn and mock, etc." (Dang, 2011). In addition, netizens open the home address, telephone number, working unite, name of relatives and other information of the victim through cyber manhunt, which finally affect the actual punishment for the victim. This kind of behavior disturbs the regular work and life of the victims largely.

The largest characteristic of irrational abuse is in science. (Yuan, 2009) Most of the netizens carrying out language violence do not know the reality well. However, the main bodies of network forums are the groups with low education degree and low income. Under this kind of condition, irrational abuse will become more and more.

In recent years, tragedies caused by the manhunt happened frequently, event some of the parties committed suicide. In December 2013, a girl committed suicide because of manhunt for she was under suspicion of stealing clothes. (Minshang Net, 2013) The calls for the legislation on the banning of manhunt become more in China.

In the effect of polarization, the speech of the netizen in the network forums would be out of control. In the forums, the netizen form the group, and in the group, most of them would reach a similar opinion after discussion, and the opinion would be reinforced eventually. With the accumulation of group impulse and emotion, the group would take action in reality. One kind of the action is manhunt.

3) Stereotype: a large amount of posts in network forums are attacks to government, intellectual and doctors. In 
fact, this is a kind of stereotype. If deep researches are carried out for those posts, we can find that most of the posts are not in line with the truth. The effect of the stereotype causes the netizen, whose knowledge is limited, have the deep-rooted prejudice for some spheres and professions. From some common words we can find the existence of the stereotype, such as the homophonic method: "civil servant (Gong Wu Yuan)" called as "Gongwu ape (Gong Wu Yuan)", "expert (Zhuanjia)" called as "brick expert (zhuanjia)", "professors (Jiaoshou)" called as "Jiao Beast (Jiaoshou)". In recent years, once there are news about "rich second generation" and "officials", netizens would always abuse and blame them indiscriminately.

In the forums, city inspector is one of the most stigmatized occupations in forums. "Gangdom", "rogue" and "hired thug" are the pronouns of city inspector. And city inspectors become the synonym of extremely bad conducts. The stereotype in network forums further influences the news report and misleads the descriptions of news reports. In news reports, verbs expressing violent actions are commonly used to describe city inspectors, such as "throw", "drag", "kick" and "abuse", etc. (Ji, 2012)

The formation of the stereotype is associated with the real condition, but more related to the emotions of the disadvantaged groups. Because of the wide gap of wealth, the disadvantaged groups cannot find ways to relieve their emotions. Therefore, those special social groups are attacked in the forums.

In network, stereotype effect is also related to the propagation of the news. The negative reports, especially of the government for the anti-corruption reasons, the doctors for the frequent medical disputes and the intellectual, appear in the news from time to time. The negative reports would be reproduced and discussed in the network forums, and then the extreme opinions would come into being during the process because of the polarization effect. The extreme opinions would influence the report in the mainstream media in turn, so the vicious circle acts.

4) Collective unconscious impulse: American philosopher Cass Sunstein thinks that group members are with certain trends from the very beginning. After negotiations, they move further in their direction and form extreme opinions. Compared with individual consciousness, group consciousness is blurry. In the network forums, such polarized impulsion would make people believe some false news. "The phenomenon of polarized group in network' would feed the false news which is not based on the fact but on the "polarization of the group'." (Han, 2012)

It's worth noting that once the group consciousness forms, every individual consciousness in the group will tend to become extreme. In The Crowd, French psychologist Gustave Le Bon thought groups are impulsive, impatient and changeful. They are vulnerable to believe easily and receive suggestions and with pure and exaggerate emotions and ignorance. (Le Bon, 2001) The matters are thought impossible in individual consciousness are reasonable in collective consciousness. Therefore, the discussion in network forums can be developed to extreme collective consciousness easily.

The effect of group polarization is obvious in the process. After the discussion of the group, some opinions are reinforced, and most of the netizen would have the same understanding of the issues in the forum. The speech in the forum would become extremely irrational with the collective unconscious impulse.

Most of Chinese netizens are not well educated. They would form the extreme collective unconsciousness in the condition they lack of independent judgment. In the internet form mentioned above, we would find that most of the viewpoints are very monotonous. Such viewpoints would have no rational thinking and are not right exactly. That would give rise to the negative effects in the real world. For example, in the case of Yao jiaxin of 2011, the extreme speech on internet, which was caused by the effect of group polarization, affect the fair trial of the judicial organ. In this case, numerous netizens with different identification has the same goal to condemn and curse Yao Jiaxin and express their angry. Although Yao Jiaxin's crime of murder was vicious and astonishing, the huge collective unconscious impulse depressed some rational voice and the result was that Yao Jiaxin was executed soon in the overwhelming curses.

5) Rife rumors. The anonymity and virtuality make the netizens give the irresponsible remarks. Some posts even become the source of the rumors. The subjects have all kind of identified labels in the traditional society, but in the network, the labels are inexistent, and they would shake off the pressure from public opinions, moral denunciations and legal sanctions. (Chen, 2011) In such condition, the rumormonger would be unscrupulous. Some extreme posts would not be convincing in first sight, but lots of people believe the posts even so the contents of the posts are almost absurd, but some people still believe the contents. Some of the contents even become the news. In the condition of information asymmetry, most of the netizens have the mentality of Pascal's Wager, which means that believing something would bring some benefit when the cost is very little, and the cost would be very huge when the subject does not believe the matter. So the subject would choose to believe in the 
condition of Pascal's Wager. Besides, the characteristic of flock effect is another factor of the spread of internet rumors.

The rumors are often rising from the spheres of housing price, food, doctor-patient relationship and social class contradictory etc. The spheres are very sensitive in China, so the rumors are very common in such spheres. The rumors would be easily spread and believed because that the disputes and contradictions are very many. The rumor mongers deliberately make the rumors in order to let off steam. So the discontent of the subject is one of the important sources of rumors.

The phenomenon of rumors in the network forums are related to the fact that the public has no appropriate place to appeal. In 2009, a survey which the Chinese Youth Daily delegate the Tencent to conduct showed that the ways in which the netizens choose to report are cyber exposure(35.8\%), traditional media exposure(31.3\%), reporting to the discipline inspection commission(17.2\%), reporting to the procurator ate (11.4\%), reporting to the superior government agency $(3.3 \%)$ and reporting to the police $(0.5 \%)$. The survey showed that the appropriate places the public appeal is very limited. So the internet is the best place to appeal. With the characteristics of anonymity, virtuality and flock effects, the extreme emotion and rumors would easily be formed. "In the network, people find a public sphere where the fear and restrict do not existed. The excited emotions and intense criticisms are as violent just as the flood getting out of the sluice gate. That shows why in China the new media is more irrational and has less calmness compare to other media." (Zhang, 2010)

Network provides the discontented netizens with a new sphere. The social structure of the network is flattening, and the time and space is compressed and surpassed by the network. As a result, in the network, the traditional social structure is destroyed, and a decentralized and flattening network structure is formed. (Zhong, 2005) Such new social structure is in favor of the freedom and interactivity of the netizens' speech. But it also feeds the misconduct of speech. For example, on July 21, 2012, a driver was trapped in his car when the flood came and at last died. The event was discussed overwhelmingly soon in the forums, but soon some rumors came into being, which said that the driver had a mistress, who came in the first time when he died. Some rumors said the driver was an idiot and he had a very weak body, so he could not get out of the car when the flood came. The rumors were so widespread that his heartsick wife had to clear the fact four days after he died. (Huang, 2012)

Although some of the rumors are obviously unconvincing and lots of the netizens do not believe them at first, but the rumors will influence the netizen greatly ultimately because of sleeper effect. In the news of the mainstream media, there is some information comes from the forums, which is very informal. The phenomenon is harmful to the stability of the society, because in the process, some of the rumors become the formal news.

The emerge of the internet technology gives life to a brand new social cultural space through a virtual cyberspace. Such social cultural space is the realistic way for human to expand their activities. That draws human's activities to appear in such new sphere. ( $\mathrm{Li}, 2007)$ The irrational expression reflects the depressed collective unconsciousness. The violent emotion restrains the rationality, and the unconscionable behaviors become popular in network. The mighty social impulsive behavior is formed after the individual emotions are gathered together. $(\mathrm{Wu}, 1998)$ It is necessary to keep a watchful eye on the irrational chaotic phenomena and to guide such speech and behavior in the network.

\section{Conclusion}

With the analysis of the main forums of the Netease, it is obvious that the network forums become the windows for the netizens to release their emotions. Although there is some real and useful information in the network forums, most of the forum information is like rubbish or harmful. The forums have the characteristics of the crowd described by Gustav Le Bon. The individuals imitate each other unconsciously and reach the almost same opinion ultimately. With the effects of polarization, sleeper and stereotype, the rumors and extreme speech would be formed, and the influence of those is harmful to the social stability.

The posters and the ones who reply in the forums are anonymous, so some netizens are not responsible for their speech. In this sense, the network forums are the world out of control, although the extremely irresponsible netizens could be tracked by the computer technology. That characteristic produces the biggest difference between the real world and the virtual world of network forums. The theories on the group in the real world can also explain the group formed in the network forums. Compared to the group in the real world, the netizen group is not only anonymous, but also more radical and extreme because of the instant communication and wider spread of the network. Although the virtual world seems isolated from the real world, but it influence the real world all the time. A watchful eye, which is different from the eye on the real world group, should be kept on the negative effects of network forums. 


\section{References}

Chen, D. (2011). Ethical Dilemma of Internet Democracy in the Development Course and Reestablishment of its Ethical Order. Journal of Yunan School of Administration, (4), 88-90.

Chen, Y., \& He, Z. (2003). The Complementation and Interaction between Network Forum and Newspaper. The Practice of News, (11), 63-64.

Cheng, Y. (2000). Chinese Association of Journalist Propose to Establish Chinese Media Network Forum. News Publishing Daily.

CNNIC. (2013). CNNIC 32nd Internet Report. Retrieved July 17, 2013, from http://tech.163.com/special/cnnic32

Dang, Y. (2011). Study on the Genre of Language Violence. Journal of Qiongzhou College, (4) 110-112.

Ge, C. (2009). Discussion on the Forming of Public Opinion in High School Network Forum. Journal of Nanyang Nomal College, (11). 96-99.

Han, L. (2012). The Influence of Polarization of Internet Group and the Messages from the Netizens on the Formation of Public Opinion. Interview and Edition, (3), 14-15.

Huang, S. (2012). Widow of the Driver Who Died of Drowning in Guangqu: The Language on Internet Is Too Vicious. Channel Daily.

Ji, X. (2012). Construction of the City Management Image by Network Media: Based on the Quantitative Analysis of Chinese Merchant Net. Today's Mass-media, (2), 92-93.

Jiang, H. (2006). The Effective Control on the Guidance of Public Opinion of Public Forum. Theoretical Observation, (1), 118-119.

Jiang, Y. (2002). Discussing the Typical Appearance of the Chat on Internet in the Perspective of Network Forum. Journal of Liuzhou Vocational \& Technical College, (4), 56-59.

Le Bon, G. (2001). The Crowd: A Study of the Popular Mind (pp. 11-13). Dover Publications, INC.

Li, Y. (2007). Behavior Anomie in Network (p. 63). Beijing: Social Science Document Publishing House.

Luo, H. (1999). The Common Concepts of Internet. Electronic Technology, (9), 20.

Ma, B., \& Ma, Y. (1999). Good Place for Talking Everything under the Sun: Network Forum. The Research and Information of Chinese Medicine, (9), 25.

Meng, C. (2001). The Development Trend of Chinese News Media Network Forum. China Publishing, (3), 28-29.

Minshang Net. (2013). The Girl Under Suspicion of Stealing Clothes Committed Suicide: The Necessity to Legislate on the Banning of Manhunt. Retrieved December 16, 2013, from http://www.mszz.cn/2013/mssp/1216/105127.html

Wang, T. (2006). The Standard of Order in Harmonious Network Forum. Hongqi Manuscript, (9), 34-36.

Wu, K. (1998). New Social Theory: The study on Chinese Social Mentality in the Transformation Period. Changsha: Hunan People's Publishing House.

Yang, L. (2008). The Exploration on the Communication Model of Network Forum. Journal of Guangxi University, (3), 139.

Yang, X. (2004). On the Development and Utilization of Network Forum Information. The Science of Information, (8), 960-963.

Yuan, W. (2009). Source of Language Violence. Economic Observation Daily.

Zhang, S. (2010). Cyber Public Opinion and Public Policy: Dialogue between Authority and Right (p. 53). Beijing: Fudan University Press.

Zhong, Y. (2005). Ethic of Network Communication (p. 192). Tsinghua University Publishing House.

Zhuang, J. (2010). The quantitative analysis of BBS based on Social Network Analysis and Data Mining. Master thesis. Chongqing University.

\section{Copyrights}

Copyright for this article is retained by the author(s), with first publication rights granted to the journal.

This is an open-access article distributed under the terms and conditions of the Creative Commons Attribution license (http://creativecommons.org/licenses/by/3.0/). 